NASA Technical Memorandum 104266

$$
\begin{gathered}
\text { M-OS } \\
142861 \\
p .18
\end{gathered}
$$

\title{
Operational and Research Aspects of a Radio- Controlled Model Flight Test Program
}

Gerald D. Budd, Ronald L. Gilman, and David Eichstedt 
NASA Technical Memorandum 104266

\section{Operational and Research Aspects of a Radio- Controlled Model Flight Test Program}

Gerald D. Budd

Dryden Flight Research Facility

Edwards, California

Ronald L. Gilman and David Eichstedt

PRC Inc.

Edwards, California

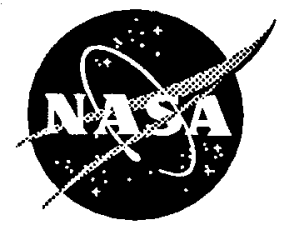

National Aeronautics and

Space Administration

Dryden Flight Research Facility

1993 


\title{
Operational and Research Aspects of a Radio-Controlled Model Flight Test Program
}

\author{
Gerald D. Budd* \\ NASA Dryden Flight Research Facility \\ Edwards, California 93523-0273 \\ Ronald L. Gilman, ${ }^{* *}$ and David Eichstedt ${ }^{\dagger}$ \\ PRC Inc. \\ Edwards, California 93523
}

\begin{abstract}
The operational and research aspects of a subscale, radio-controlled model flight test program are presented. By using low-cost free-flying models, an approach was developed for obtaining research-quality vehicle performance and aerodynamic information. The advantages and limitations learned by applying this approach to a specific flight test program are described. The research quality of the data acquired shows that model flight testing is practical for obtaining consistent and repeatable flight data.
\end{abstract}

\section{Nomenclature}

$\begin{array}{ll}a_{x} & \text { axial acceleration, } g \\ a_{n} & \text { normal acceleration, } g \\ \text { c.g. } & \text { center of gravity } \\ \text { CPT } & \text { control position transducer } \\ \mathrm{K} & \text { transmitter mixing control gain } \\ \text { L/D } & \text { lift-to-drag ratio } \\ \text { POPU } & \text { pushover-pullup } \\ \bar{q} & \text { dynamic pressure, lb/ } \mathrm{ft}^{2} \\ \alpha & \text { angle of attack, deg } \\ \delta_{e_{l}} & \text { left elevator deflection, deg } \\ \delta_{e_{r}} & \text { right elevator deflection, deg } \\ \Delta a_{x} & \text { axial acceleration increment, } g \\ \Delta_{p_{l}} & \text { left engine fan pressure }\end{array}$

\footnotetext{
*Aerospace Engineer.

** Senior Research Model Engineer. AIAA member.

${ }^{\dagger}$ Aeronautical Engineer. AIAA member. Copyright (C) 1993 by the American Institute of Aeronautics and Astronautics, Inc. No copyright is asserted in the United States under Title 17, U.S. Code. The U.S. Government has a royalty-free license to exercise all rights under the copyright claimed herein for Governmental purposes. All other rights are reserved by the copyright owner.
}

\author{
$\Delta_{p_{r}} \quad$ right engine fan pressure \\ $\Delta \mathrm{T} \quad$ thrust increment, lb
}

\section{Introduction}

For the design of a new aircraft, data from many hours of wind-tunnel testing and computational analysis are required before a basic configuration can be defined. While these data are required, flight-derived aerodynamic data acquired early in the design process can add useful information about the configuration, especially for unconventional configurations. In the past, studies performed using free-flying subscale research models to obtain aerodynamic data provided flight data with limited success.

Previous subscale unmanned research vehicles have been either large, heavy, unpowered aircraft (Refs. 1 through 4) or small models that were usually very lightweight and could takeoff and land under their own power (Refs. 5 through 8 ). The larger vehicles have usually been equipped with standard aircraft flight test data acquisition systems, while the smaller models have typically been minimally instrumented because of weight considerations. As a result, most prior studies using the smaller models have focused on qualitative results such as pilot comments on general handling and flying qualities.

Recent advances in technology concerning lightweight composite structures, efficient miniature ducted-fan propulsion systems, and reliable uplink flight control systems have made small model flight testing practical. In particular, the availability of inexpensive, lightweight, research-quality data acquisition systems makes it easier to instrument the smaller models.

Recently, a flight test program using a subscale, radio-controlled research model of a low lift-to-drag (L/D) ratio vehicle was completed at the NASA Dryden Flight Research Facility. The program objectives 
included demonstrating powered flight for the landing configuration of the vehicle and documenting the measured vehicle low-speed flight characteristics using an onboard, research-quality, data acquisition system. Off-the-shelf model aircraft hardware was used wherever possible to reduce cost, time, and overhead. An effort was also made to operate with a minimal flight crew and to eliminate the use of dedicated test range and control room facilities.

This report describes the operational and research aspects of the model flight test program. Presented also are examples of test results to help evaluate the research value of the approach and test methods obtained using a low-cost free-flying model. This report documents the advantages and limitations learned by applying a subscale model approach to a specific flight test program. A typical flight operation and research flight plan are described.

\section{Vehicle Description}

The vehicle tested was a subscale model of a classified, advanced hypersonic configuration with an unusually low subsonic L/D ratio (Fig. 1). This L/D characteristic, coupled with a requirement for the vehicle to takeoff under its own power, forced the design of a light model with a powerful internal propulsion system. The resulting aircraft was 104 in. long and weighed approximately $28.2 \mathrm{lb}$ (Table 1 ). It was powered by two model aircraft ducted-fan systems, which produce about 10 static pounds of thrust each. It also employed a pneumatically operated, retractable landing gear system for conventional takeoff and landing capability.

Table 1. Component weights of model.

\begin{tabular}{lcc}
\hline Component & Weight, lb & Percent of total \\
\hline Baseline structure & 9.5 & 33.69 \\
Propulsion system & 7.0 & 24.82 \\
Flight control system* & 2.1 & 7.45 \\
Fuel & 3.1 & 10.99 \\
Landing gear & 3.5 & 12.41 \\
Instrumentation* & 3.0 & 10.64 \\
\hline Total & 28.2 & 100.00 \\
\hline
\end{tabular}

*Includes batteries.

\section{Construction and Materials}

Because of the size and shape of the aircraft, fiberglass construction techniques used in aircraft or sailplanes were considered too heavy to produce a suitably stiff fuselage shell. A slightly different technique, therefore, was developed. Several sample layups of fiberglass, polystyrene foam, Kevlar ${ }^{\mathrm{TM}}$ (DuPont, Inc., Wilmington, Delaware), and combinations of the three were produced. The sample layups were then weighed and examined by hand for relative stiffness. A sandwich of Kevlar, expanded bead polystyrene foam, and Kevlar was found to produce the desired stiffness at low weight for the fuselage outer shell (sample 1 in Table 2). The material selected maintained good formability and fabrication characteristics.

The fuselage load-carrying bulkheads were built from a sandwich combination of fiberglass and end-grain balsa wood that resulted in components of sufficient strength and low weight. At high-stress locations such as landing gear and wing spar attach points, preimpregnated carbon fiber strips were used to reinforce the bulkheads.

The fuselage shell was constructed from two halfshells bonded together after the bulkheads were bonded in place. At locations where the bulkheads were adhered to the fuselage shell, the shell had to be prepared during the molding process. Bulkhead locations were determined before molding the fuselage. At these locations, foam material was left out of the sandwich, allowing the inner layers of Kevlar to come into contact with the outer layers while maintaining outer surface contours. A 2-in. wide strip of Kevlar tape was added to the inner surface to add stiffness to the joint. The bulkheads were then bonded to the fuselage shell. These fabrication steps successfully prevented delamination of the sandwich material. Figure 2 shows a detailed cross-section of a typical bulkhead joint.

Wing and tail surfaces were constructed of expanded bead polystyrene foam, cut to shape with a hot-wire, sheeted with balsa wood, and finished with heat-shrink, iron-on Mylar ${ }^{\mathrm{TM}}$ (DuPont, Inc., Circleville, Ohio). Spars were of plywood, balsa, and carbon fiber. The wing and tail surfaces were removable for repair and maintenance.

\section{Propulsion System}

To properly model the vehicle geometry of many jetor rocket-powered aircraft, it is necessary to use an internally contained propulsion system, such as a ducted fan. The ducted-fan propulsion system eliminates the flow-field disturbances induced by the protruding propeller blades typical mounted propeller systems. Recent advances in ducted-fan technology (Ref. 9) have yielded substantial increases in performance that enabled this flight test program to be successful. For this vehicle, propulsion was provided by two highperformance model aircraft ducted-fan systems (Fig. 3) that were mounted internal to the fuselage to simulate jet engines. Each 4.6-in. diameter fan rotor was driven directly by an alcohol-powered, single cylinder, two-stroke model airplane engine of $0.82 \mathrm{in}^{3}$ displacement. To minimize the pressure-reducing effects of airflow blockage by the cylinder head, these fan units incorporated area ruling into the fan shroud and proper streamlining around the cylinder heads. 
Table 2. Structural test specimens.

\begin{tabular}{|c|c|c|c|c|}
\hline Sample & $\begin{array}{l}\text { Layer } \\
\text { location }\end{array}$ & Material & $\begin{array}{c}\text { Sample } \\
\text { weight, oz } / \mathrm{ft}^{2}\end{array}$ & $\begin{array}{l}\text { Relative } \\
\text { stiffness }\end{array}$ \\
\hline \multirow[t]{3}{*}{$1^{*}$} & Inner & Kevlar & 1.85 & Stiff \\
\hline & Core & 0.10 -in. expanded foam & & \\
\hline & Outer & Kevlar & & \\
\hline \multirow[t]{3}{*}{2} & Inner & Kevlar & 1.85 & Stiff \\
\hline & Core & 0.10 -in. extruded foam & & \\
\hline & Outer & Kevlar & & \\
\hline \multirow[t]{3}{*}{3} & Inner & Kevlar & 2.45 & Stiff \\
\hline & Core & 0.10 -in. extruded foam & & \\
\hline & Outer & Kevlar (2 layers) & & \\
\hline \multirow[t]{3}{*}{4} & Inner & Kevlar (2 layers) & 3.00 & Stiff \\
\hline & Core & 0.10 -in. extruded foam & & \\
\hline & Outer & Kevlar (2 layers) & & \\
\hline \multirow[t]{4}{*}{5} & Inner & Fiberglass $\left(2 \mathrm{oz} / \mathrm{yd}^{2}\right)$ & 2.45 & Flexible \\
\hline & - & Kevlar & & \\
\hline & - & Fiberglass $\left(4 \mathrm{oz} / \mathrm{yd}^{2}\right)$ & & \\
\hline & Outer & Fiberglass $\left(2 \mathrm{oz} / \mathrm{yd}^{2}\right)$ & & \\
\hline \multirow[t]{2}{*}{6} & Inner & Fiberglass $\left(6 \mathrm{oz} / \mathrm{yd}^{2}\right)$ & 1.55 & Flexible \\
\hline & Outer & Fiberglass $\left(2 \mathrm{oz} / \mathrm{yd}^{2}\right)$ & & \\
\hline \multirow[t]{2}{*}{7} & Inner & Fiberglass $\left(10 \mathrm{oz} / \mathrm{yd}^{2}\right)$ & 2.27 & Flexible \\
\hline & Outer & Fiberglass $\left(2 \mathrm{oz} / \mathrm{yd}^{2}\right)$ & & \\
\hline \multirow[t]{3}{*}{8} & Inner & Fiberglass $(3 \mathrm{oz})$ & 2.26 & Stiff \\
\hline & Core & 0.10 -in. extruded foam & & \\
\hline & Outer & Fiberglass $\left(3 \mathrm{oz} / \mathrm{yd}^{2}\right)$ & & \\
\hline \multirow[t]{3}{*}{9} & Inner & Fiberglass $\left(3 \mathrm{oz} / \mathrm{yd}^{2}\right)$ & 2.17 & Stiff \\
\hline & Core & 0.10 -in. extruded foam & & \\
\hline & Outer & Kevlar & & \\
\hline \multirow[t]{3}{*}{10} & Inner & Kevlar & 2.54 & Stiff \\
\hline & Core & 0.10 -in extruded foam & & \\
\hline & Outer & Fiberglass $\left(6 \mathrm{oz} / \mathrm{yd}^{2}\right)$ & & \\
\hline
\end{tabular}

${ }^{*}$ Selected for fuselage outer shell.

Note: Expanded bead polystyrene foam was $1.0 \mathrm{lb} / \mathrm{ft}^{3}$ density. Extruded polystyrene foam was $1.5 \mathrm{lb} / \mathrm{ft}^{3}$ density.

Kevlar cloth weight was $1.8 \mathrm{oz} / \mathrm{yd}^{2}$.

In addition, streamlining was incorporated behind the engine crankcases. The engines could be throttled and produced approximately $10 \mathrm{lb}$ of static thrust per engine. Limitations in available fuel capacity restricted flights to no more than 5 min duration.

The propulsion system was calibrated for thrust in a low-speed wind tunnel using a rounded-lip inlet and a tailpipe assembly representative of the vehicle's tailpipe assembly. Thrust was measured as a function of dynamic pressure and differential static pressure across the rotor fan blades. A correlation was developed for thrust, dynamic pressure, and differential fan pressure that allowed for the calculation of the estimated in-flight thrust. Angle-of-attack and sideslip effects were not incorporated into this calibration.

\section{Uplink Flight Control System}

The flight control system used for uplink control of the vehicle was a commercially available nine-channel, digital pulse code modulation radio control system with 10 -bit resolution. The radio control system was considered highly reliable in contrast to systems used previously. No redundant control system was used, since the loss of the model was considered an acceptable risk. The transmitter employed a software-controllable flight control system that greatly simplified vehicle operation. Multiple control surface gain schedules incorporating both linear and exponential stick gearing were available to tailor the handling characteristics as required. Servo actuator deflection limits were independently adjustable within the control system in both positive and negative directions. Power for both 
the uplink transmitter and the onboard flight control system was provided by rechargeable nickle-cadmium batteries.

The system software permitted mixing of several different control functions before transmitting. For example, the project aircraft used elevons (combination of elevators and ailerons), so an option in the flight control system software was configured to mix both pitch and roll stick commands into individual servo actuator commands for right and left elevons. Roll stick command was also mixed to command a small amount (10 percent) of coordinating rudder deflection to minimize adverse yaw and to help increase the vehicle's turn rate. Figure 4 shows a diagram of the flight control laws used for this vehicle.

The transmitter output power was boosted with an external amplifier from $500 \mathrm{~mW}$ to $5 \mathrm{~W}$ to ensure adequate receiver performance. The external amplifier was powered with an automotive-type, 12-V lead acid battery. Additionally, the onboard flight control receiver featured an automatic fail-safe system used to disable the data acquisition system in the event of internal or external uplink interference. The fail-safe system was configured so that if the uplink receiver detected a momentary loss of signal, the receiver would remove power from the instrumentation system until the uplink signal was restored. Figure 5 shows the ground-based portion of the uplink flight control system hardware.

\section{Miniature Data Acquisition System}

A miniature data logger system (described in Ref. 10 and shown in Fig. 6) recorded data onboard the vehicle during flight. The system has eight analog data channels operating at 25 samples/sec with 10 -bit resolution (Table 3). A total of 150 kilobytes of onboard memory allowed up to $6 \mathrm{~min}$ of data acquisition during each flight. The data were filtered with a three-pole, low-pass, antialiasing filter with a rolloff frequency of $10 \mathrm{~Hz}$. The data acquisition system contained a small lithium backup battery so that recorded data would not be lost. Primary data system power was provided by small, rechargeable nickle-cadmium batteries. After the flight was complete, the data were downloaded to a personal computer for conversion to engineering units and postflight analysis.

\section{Flight Operations}

A minimum flight crew was required to conduct a research flight, along with portable equipment and supplies necessary to support test activities at a remote test site. A flight test plan also was needed to provide an efficient and structured flight test sequence. The following sections describe these elements of flight operations.

\section{Test Personnel}

A typical research flight was staffed with a minimum crew of five: the pilot, flight test engineer, instrumentation engineer, vehicle crew chief, and video camera operator. Because of the classified nature of the model, the flights were conducted at a remote location where manpower and other available resources were scarce. Each crewmember was skilled in more than a single discipline, and added staffing would be necessary to conduct a flight operation if a less experienced flight crew were used. Job functions were frequently combined to allow for a successful flight operation.

The pilot was responsible for operating the model and performing the test maneuvers. The flight test engineer coordinated the sequencing of flight maneuvers from a predetermined flight plan and verbally communicating this information to the pilot. The instrumentation engineer maintained the data acquisition system and postflight data handling and processing. The vehicle crew chief conducted preflight and postflight vehicle operations and maintenance. The camera operator videotaped every flight for documentation purposes.

\section{Test Setup and Procedure}

A typical flight operation involved traveling to the location where the flight tests were to be conducted. The flight tests were scheduled for just after dawn when

Table 3. Sensor specifications.

\begin{tabular}{llrll}
\hline \hline Variable & Model number & Range & Resolution & Accuracy \\
\hline$\alpha, \operatorname{deg}$ & NASA-Dryden noseboom & -5 to 40 & 0.04 & 0.25 \\
$\bar{q}, \mathrm{lb} / \mathrm{ft}^{2}$ & SenSym 142SC01D & 0 to 55 & 0.058 & 0.144 \\
$\delta_{e_{l}}, \mathrm{deg} ; \delta_{e_{r}}, \operatorname{deg}$ & NASA-Dryden CPT & -40 to 20 & 0.06 & 0.20 \\
$\Delta_{p_{l}}, \mathrm{lb} / \mathrm{in}^{2} ; \Delta_{p_{r}}, \mathrm{lb} / \mathrm{in}^{2}$ & SenSym 142SC01D & 0.0 to 0.6 & 0.0006 & 0.001 \\
$a_{x}, g$ & IC Sensors 3110-002 & -1 to 1 & 0.002 & 0.015 \\
$a_{n}, g$ & IC Sensors 3110-005** & -0.5 to 2.5 & 0.003 & 0.02 \\
\hline
\end{tabular}

"SenSym Inc., Sunnyvale, California.

**IC Sensors, Milpitas, California 
atmospheric turbulence was least likely. Because of the remoteness of the test site, a travel trailer was acquired and equipped with tools and supplies needed for maintenance and repair of the test model onsite. The trailer transported the test model to and from the test site and provided the support for efficient preflight preparation of the vehicle and rapid postflight turnaround of the vehicle between flights. Upon arrival at the site, a camp was setup along one edge of the dry lakebed that served as the runway. The vehicle was unloaded, preflighted, and fueled. If the vehicle configuration had been changed since the previous flight, a weight-andbalance survey of the vehicle was performed. Finally, the instrumentation system was evaluated for functionality and initialized for flight. Preflight checklists were used in all critical areas to ensure that all vital systems and functions were operational and fully configured for flight.

When the crew chief was satisfied the vehicle was suitably prepared for flight, a brief review of the flight plan, programmed on a preplanned set of detailed flight cards (Table 4), would take place. A review of the flight sequence on the cards was conducted by the flight test engineer to ensure that all crewmembers were fully aware of their particular responsibilities during each phase of the flight. Once the flight card review was complete, the flight test engineer would instruct the pilot and the crew chief to start the propulsion system and prepare for taxi onto the runway. After engine start, the flight cards were followed until the flight was complete and postflight inspections were underway in preparation for the next scheduled flight. The flight cards provided a structured flight test sequence to optimize the time available for research maneuvers. The cards also included emergency procedures to follow if a landing approach was missed or an engine stopped.

The pilot and the flight test engineer were stationed at the center edge of a runway on the dry lakebed. The lakebed used for the flight tests is approximately $1000 \mathrm{ft}$ in diameter, providing flexibility in orienting the takeoff and landing direction into the wind to minimize the takeoff roll, and for emergency landings. A figure-eight ground track produced the longest possible useful steady, straight-flight segment between the turns at each end of the visual test range. During these straight-flight segments the flight test maneuvers were performed. As the flight endurance capability of the model was limited to $5 \mathrm{~min}$, only three or four maneuver sequences could be executed per flight. After the flight was complete, the recorded test data were downloaded to a personal computer for postflight conversion to engineering units and initial analysis.

\section{Program Results}

Several operational constraints were realized during the early portion of this flight test program. These constraints included an inability to accelerate to flying speed and transition to flight, the effects of limited visual range, uplink interference caused by the data acquisition system, and structural vibration from the reciprocating engines saturating the instrumentation accelerometers.

\section{Taxi Tests}

The first constraint encountered was that the original vehicle was unable to accelerate to fying speed and rotate into a lift-producing attitude for takeoff. As the early flights were flown uninstrumented, a handheld radar gun measured the vehicles ground speed as the vehicle traveled down marked intervals of the runway. These high-speed taxi tests were performed with the vehicles control surfaces configured in a range of positions from full trailing-edge up to smoothly faired for minimum drag. From this the vehicle was found to reach its maximum ground speed at approximately a $300 \mathrm{ft}$ distance and the maximum velocity was achieved in the faired control surface configuration. When noseup pitch control was commanded, the vehicle would slow down without exhibiting any indication of rotation into a takeoff attitude.

\section{Propulsion System Enhancement}

An effort to increase the thrust of the propulsion system was begun by tufting the inlet area of the vehicle and performing other taxi tests with video documentation. A review of the video documentation for the tufted area revealed that the vehicles flush-inlet design was drawing air from behind the inlet, prompting a change in the inlet design to a ram configuration. The ram-inlet design yielded an 82 percent increase in static thrust, from 5.5 to $10 \mathrm{lb}$ per engine. Subsequent tuft tests of the ram-inlet design confirmed the improved performance of the ram inlet.

\section{Rolling Resistance Reduction}

An effort was made to measure and reduce the vehicles rolling resistance by testing different tire and bearing combinations. The vehicle was towed down the lakebed behind a truck with a long towline and a force scale. The towing force was measured at different speeds with each tire and bearing combination. Table 5 shows the results of these tests. Based on this information, a solid molded rubber tire was chosen and adapted to a glass-filled nylon wheel modified to accept sealed ball-bearings. These modifications reduced rolling friction with a minimal increase in weight. 
Table 4. Sample flight card.

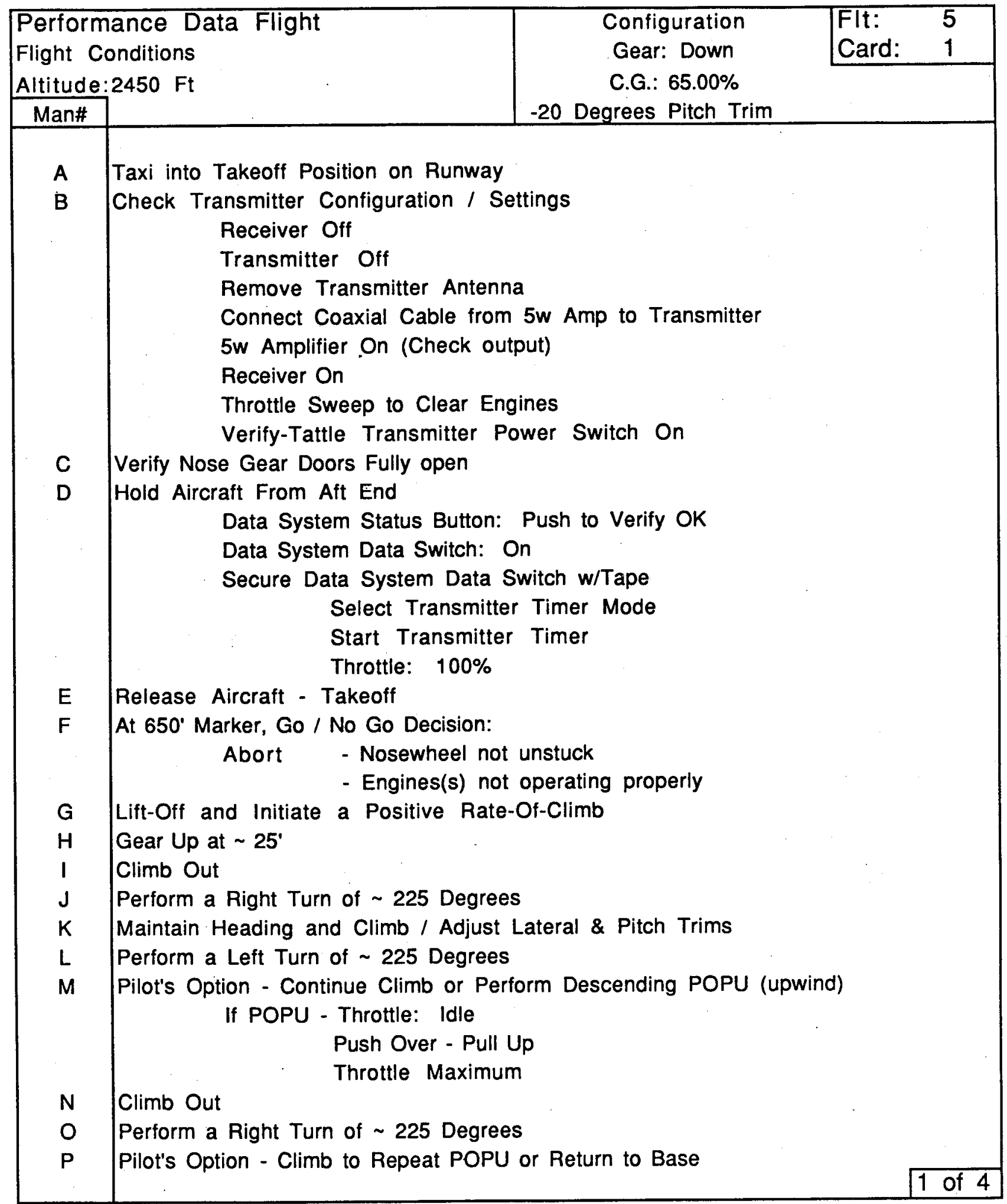


Table 5. Tow test results.

\begin{tabular}{ccccccc}
\hline \hline & \multicolumn{9}{c}{ Pull force, lb } & & Coefficient of \\
\cline { 2 - 6 } Configuration & Breakout & $5 \mathrm{mph}$ & $10 \mathrm{mph}$ & $15 \mathrm{mph}$ & Weight, lb & $\begin{array}{c}\text { rolling friction } \\
\text { rolion }\end{array}$ \\
\hline 1 & 6 & 2.5 & 4.5 & 5.5 & 26.5 & 0.2 \\
2 & --- & 2.7 & 3.5 & 4.2 & 28.2 & 0.15 \\
3 & --- & 2.2 & 2.2 & 3 & 28.2 & 0.1 \\
\hline \hline
\end{tabular}

Configuration 1: Hollow molded rubber tire with nylon hub and lubricated brass bushing inserts.

Configuration 2: Hollow molded plastic tire with nylon hub and lubricated brass bushing inserts.

Configuration 3: Solid molded rubber tire with glass-filled nylon hub and sealed ballbearing inserts.

Once these modifications were made, the vehicle could accelerate in a faired control surface configuration to a velocity sufficient for rotation and transition to flight. The radar gun measured the transition velocity (corrected for ground winds) and signaled the pilot when to apply aft stick input for rotation, thus minimizing the takeoff roll distance.

\section{Remote Pilot Techniques}

Another significant constraint was the effect of the visual range limitation on the performance of the flight test maneuvers. The low $\mathrm{L} / \mathrm{D}$ ratio of the vehicle resulted in a turn radius so large that flight within normal visual range was nearly impossible. In addition, this model had an odd symmetrical shape that made visual attitude recognition difficult and forced the adoption of unique flight procedures. The pilot could not maintain adequate visual contact to maintain a steady, level turn at an approximate distance of $2000 \mathrm{ft}$. During the distant, level turns, the flight test engineer used binoculars to assist the pilot by providing verbal cues describing the vehicles heading and attitude. No other type of controlled maneuvering, however, was possible at this distance.

Another constraint was the lack of flight condition information available for feedback to the pilot. For this program, there was no provision for real-time transmission of data to the ground, which limited the precision of performing test maneuvers at a specific flight condition. To maximize maneuver quality, each maneuver was performed several times. Before first flight, the use of a ground-based simulator was evaluated for flight planning and maneuver evaluation. The simulator was not considered an effective tool for this model flight program, since it could not provide the necessary visual range and attitude cues required by the pilot of the model. Practice sessions with a substitute model configured to have performance levels and flying qualities similar to the test model provided the most benefit in flight training and maneuver planning.

\section{Interference and Vibration Problems}

Another constraint became apparent during preflight ground testing: the uplink signal to the receiver was experiencing interference from the instrumentation system. To eliminate this problem, a 5-W signal booster was incorporated into the uplink transmitter system (Ref. 10).

Structural vibration from the reciprocating engines at full power was measured in flight to be greater than $5 \mathrm{~g}$. These vibration levels saturated the lower level accelerometers that were measuring the incremental accelerations and decelerations created by the flight test maneuvers. Different mounting techniques and locations for the engines and accelerometers were tried, but they failed to alleviate the problem.

The high level of structural vibration necessitated a modification to the test procedures to gather meaningful acceleration data. Initially, pushover-pullup (POPU) maneuvers were performed at high-power settings in steady level flight in an attempt to measure lift and drag. Ultimately, a pullup maneuver was developed that could be flown from a steep descent with the engines at an idle power setting. Under these conditions the accelerometer data were suitable for analysis.

\section{Flight Data}

Figure 7 shows time history data from a representative pullup maneuver for this vehicle (Ref. 10). The data presented are similar to flight test data acquired with full-scale aircraft (Ref. 11). In figure 7 the data analyzed were between 2 and $10 \mathrm{sec}$, which corresponds to engine idle as indicated by the minimum values of $\left(\Delta_{p_{l}}\right.$ and $\left.\Delta_{p_{r}}\right)$.

Figure 8 is constructed with L/D data taken from pullup maneuvers flown on three separate flights and gives an indication of data repeatability and consistency. The method used to derive lift and drag from the measured data is found in Ref. 12. The accelerometer data were filtered postflight with a digital low- 
pass filter with a rolloff frequency of $0.25 \mathrm{~Hz}$ to remove turbulence-induced noise. The dotted lines above and below the solid lines are estimates of the error bounds for the data based on instrumentation error estimates, data repeatability, maneuver quality, and signal-tonoise ratio. Figures 9 and 10 show the results of instrumentation sensitivity on the analyzed flight data. The data shown are an example used to indicate that it is possible to use low-cost, free-flying models to obtain high-quality research data that are consistent and repeatable.

\section{Concluding Remarks}

A flight test program using a subscale radocontrolled research model was completed at the NASA Dryden Flight Research Facility. Experience gained during this program indicates that advances in lightweight instrumentation technology allow this type of flight testing to be conducted in a timely and costeffective manner while acquiring high-quality research data. Important factors in achieving program goals with free-flying research models are to operate the test vehicle in the same mode as a typical model aircraft, to use minimum backup systems since loss of the test vehicle was an acceptable risk, and to use off-the-shelf hardware to reduce cost, time, and overhead. The research-quality data acquired during these flights illustrated that it is practical to use a low-cost, free-flying model to obtain consistent and repeatable flight data.

\section{References}

${ }^{1}$ Layton, Garrison P., "A New Experimental Flight Research Technique: The Remotely Piloted Airplane," AGARD-CP-187, Apr. 1976.

${ }^{2}$ Reed, R. Dale, Flight Research Techniques Utilizing Remotely Piloted Research Vehicles, AGARD Lecture Series No. 108, Aircraft Assessment and Acceptance Testing, June 1980.
${ }^{3}$ Wolowicz, Chester H., James S. Bowman, Jr., and William P. Gilbert, Similitude Requirements and Scaling Relationships as Applied to Model Testing, NASA TP-1435, 1979.

${ }^{4}$ Reed, R. Dale, "RPRVs: The First and Future Flights," Astronaut. E Aeronaut., Vol. 12, No. 4, Apr. 1974.

${ }^{5}$ Yip, Long P., Holly M. Ross, and David B. Robelen, Model Flight Tests of a Spin-Resistant Trainer Configuration, J. Aircraft, Vol. 29, No. 5, Sept.-Oct. 1992.

${ }^{6}$ Yip, Long P., David J. Fratello, David B. Robelen, and George M. Makowiec, Static Wind-Tunnel and Radio-Controlled Flight Test Investigation of a Remotely Piloted Vehicle Having a Delta Wing Planform, NASA TM-4200, 1990.

${ }^{7}$ Gee, Shu W., and Samuel R. Brown, Flight Tests of a Radio-Controlled Airplane Model With a Free-Wing, Free-Canard Configuration, NASA TM-72853, 1978.

${ }^{8}$ Reed, Robert D., "Flight Testing of Advanced Spacecraft Recovery Concepts Using the Aeromodelers Approach," AIAA-68-242, 1968.

${ }^{9}$ James, David, Ducted Fans for Model Jets, Argus Books, 1989.

${ }^{10}$ Hamory, Philip J. and James E. Murray, "Flight Experience with Lightweight, Low-Power Miniaturized Instrumentation Systems," AIAA-92-4111, 1992.

${ }^{11}$ Iliff, Kenneth W., "Maximum Likelihood Estimates of Lift and Drag Characteristics Obtained from Dynamic Aircraft Maneuvers," AIAA-76-024, 1976.

${ }^{12}$ Beeler, De E., Donald R. Bellman, and Edwin J. Saltzman, Flight Techniques for Determining Airplane Drag at High Mach Numbers, NACA TN-3821, Aug. 1956. 


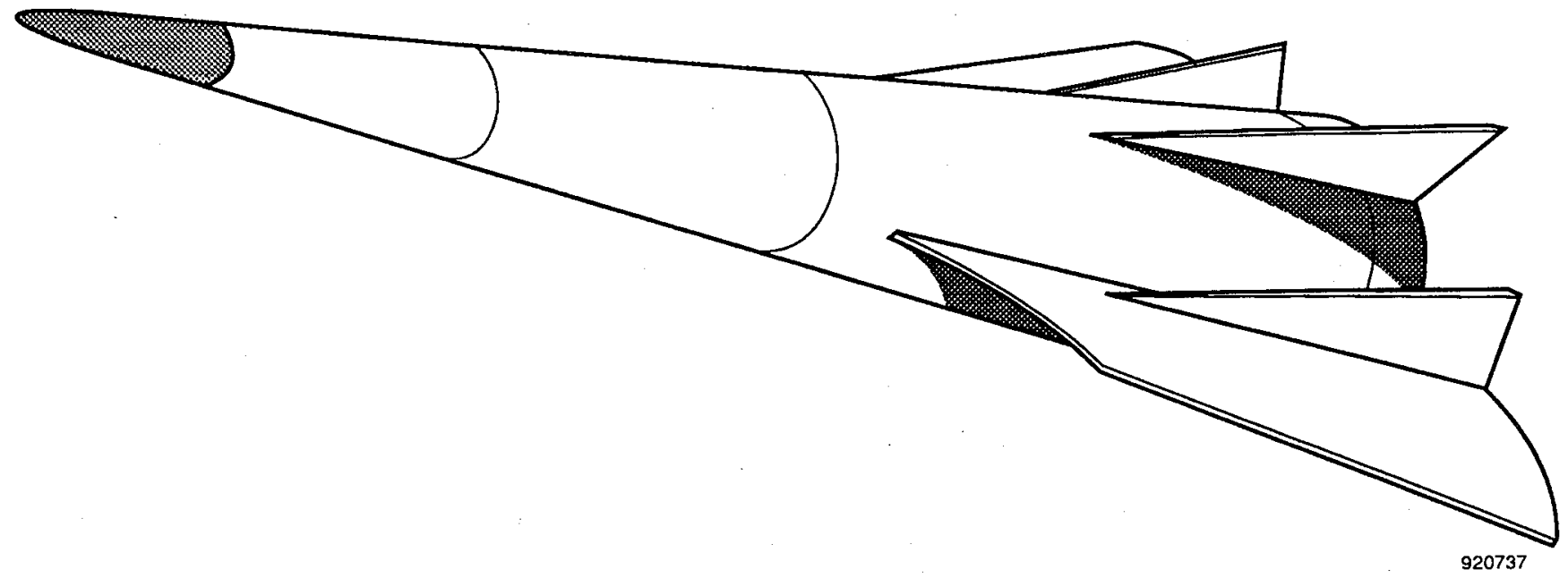

Fig. 1. Test vehicle.

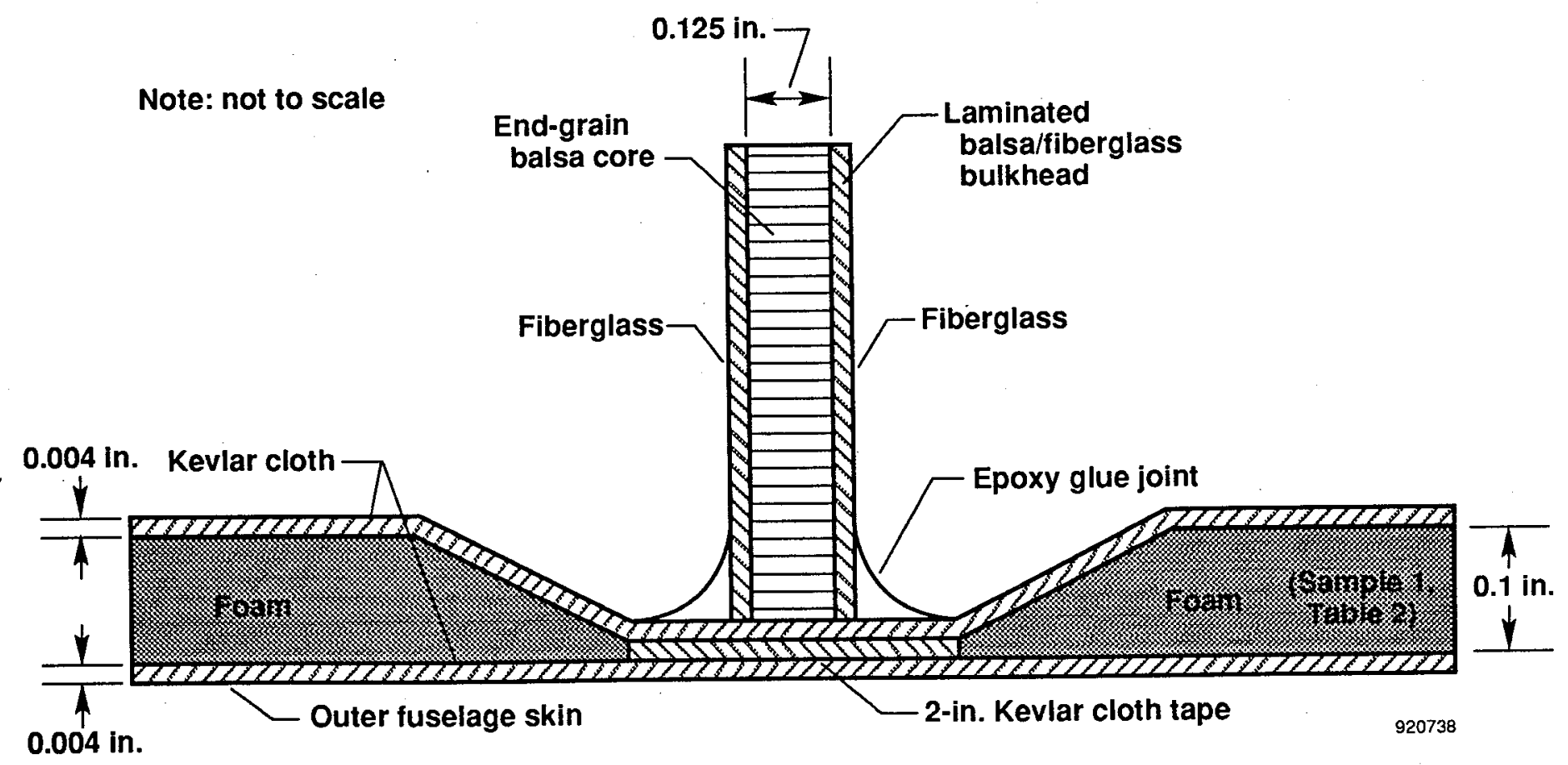

Fig. 2. Composite joint cross-section (typical dimensions shown). 


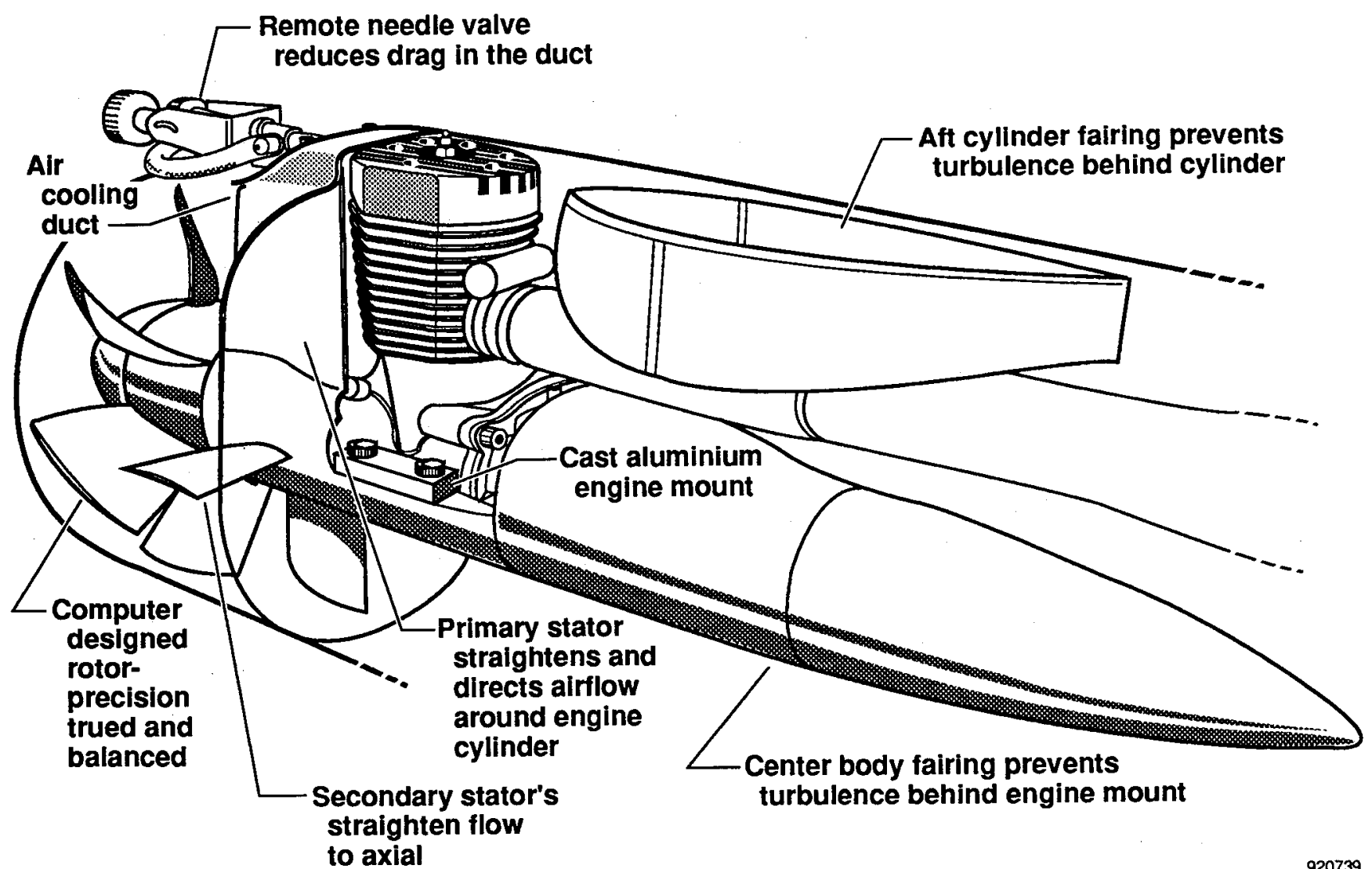

Fig. 3. Typical ducted-fan system.

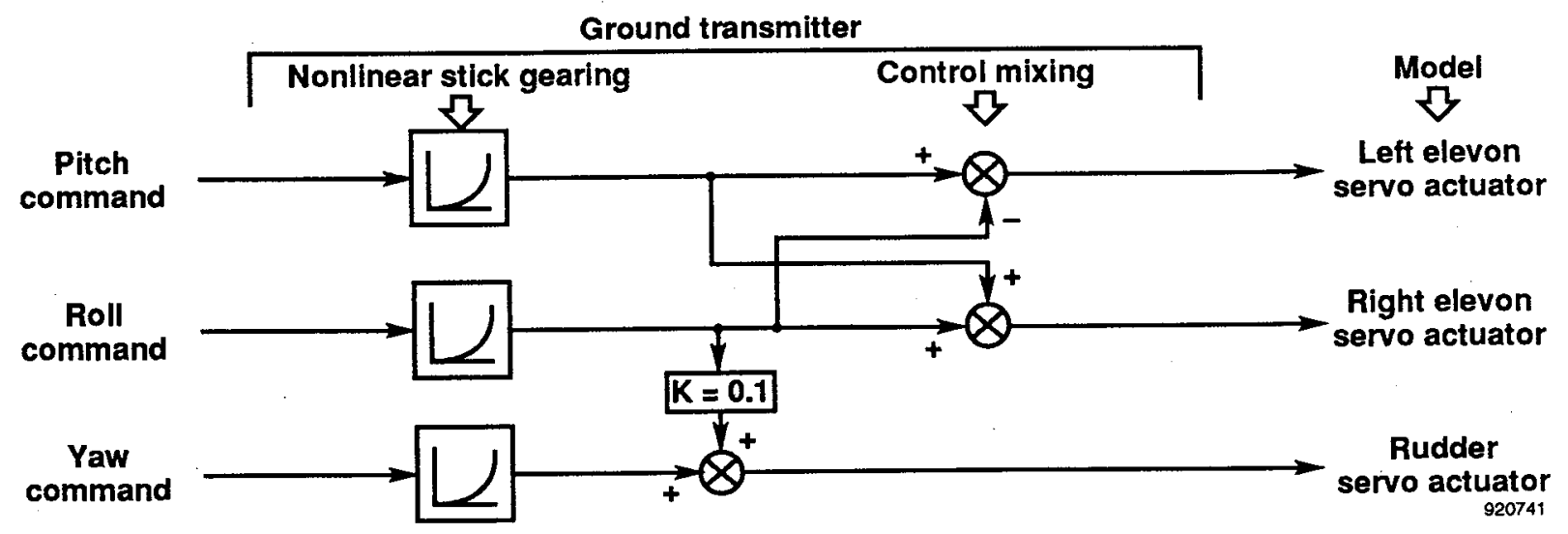

Fig. 4. Flight control system laws. 


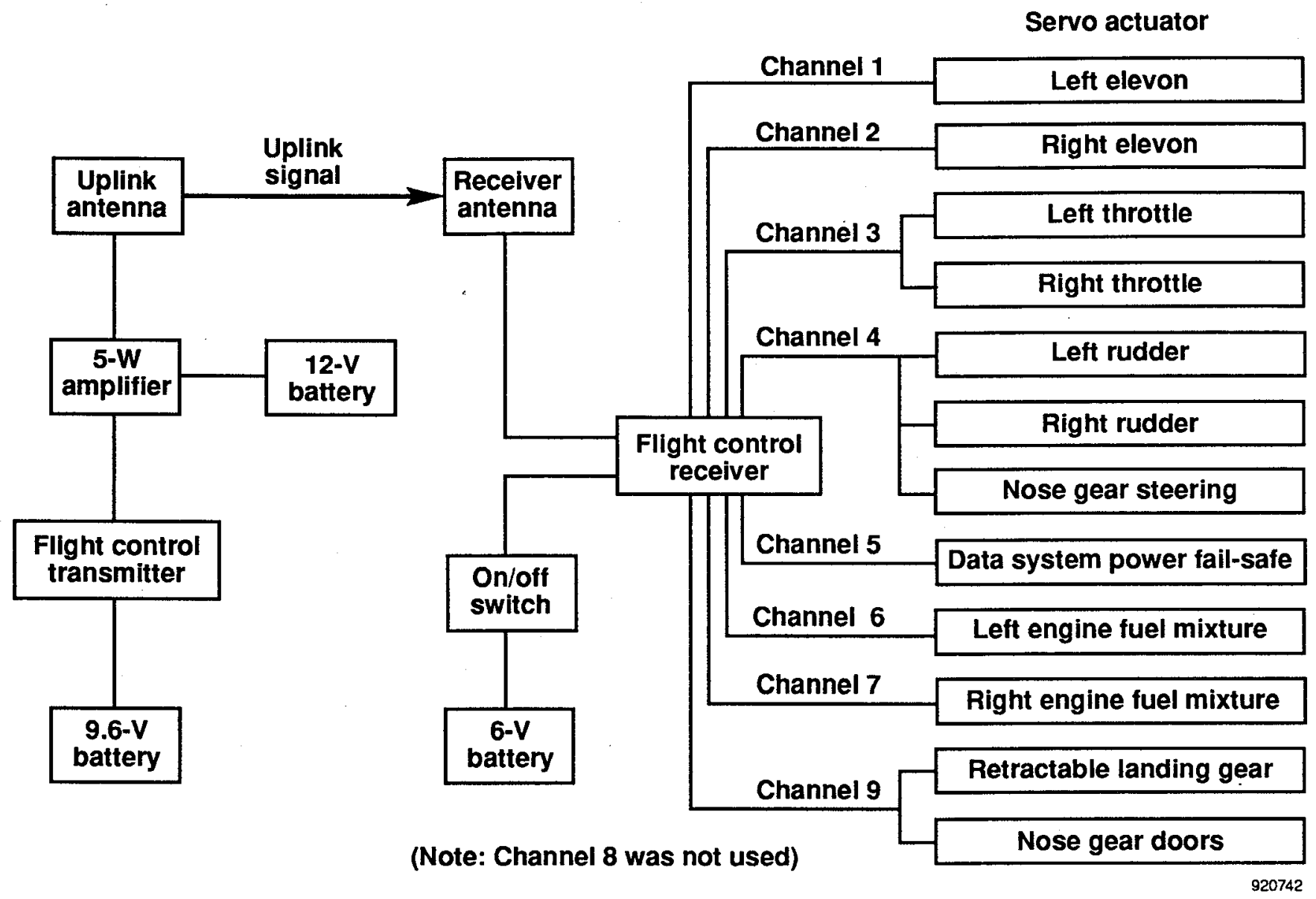

Fig. 5. Flight control system hardware. 


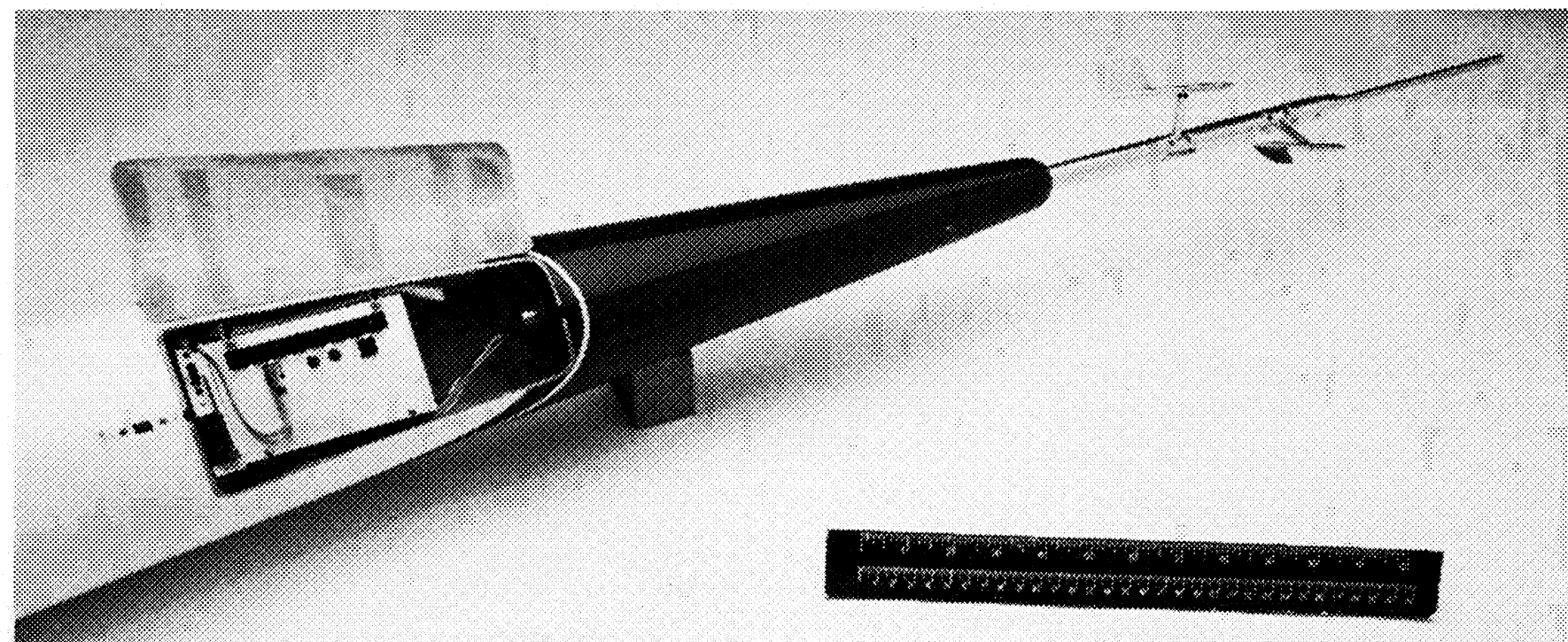

(a) Data logger and noseboom installed in model aircraft.

EC 92 05214-4

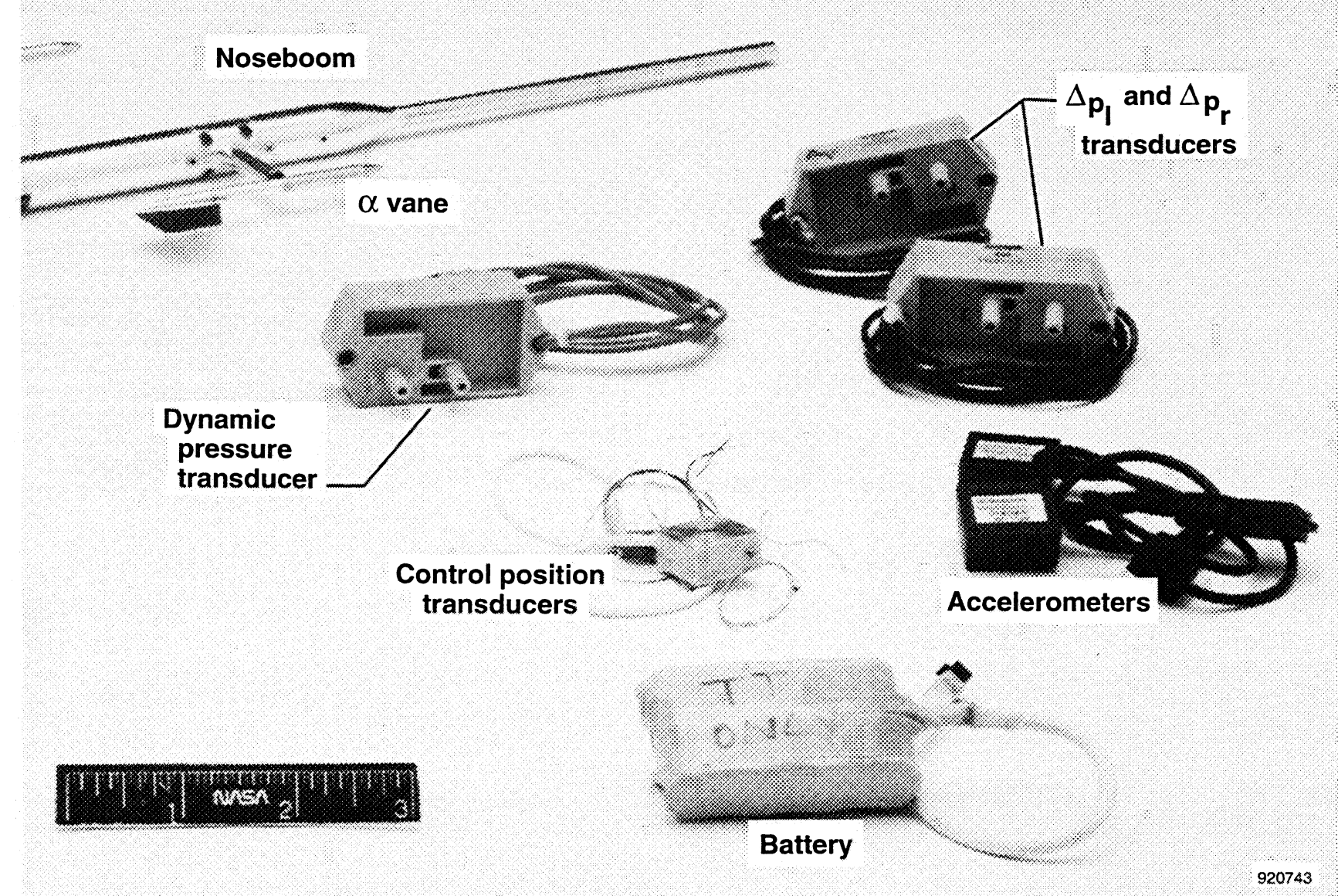

(b) Onboard data acquisition components.

Fig. 6. Miniature data acquisition system. 


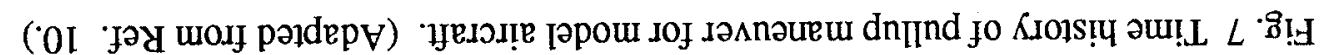

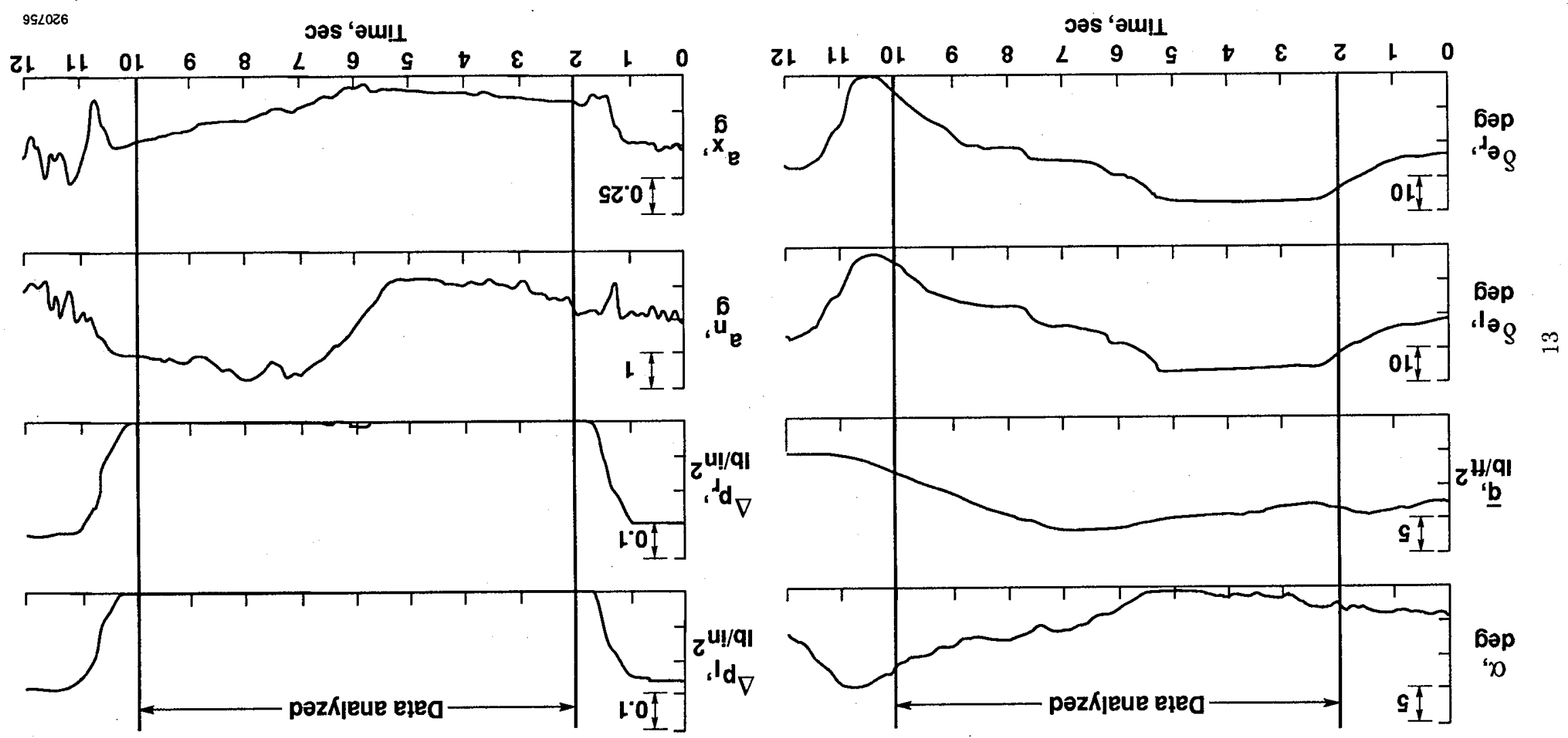




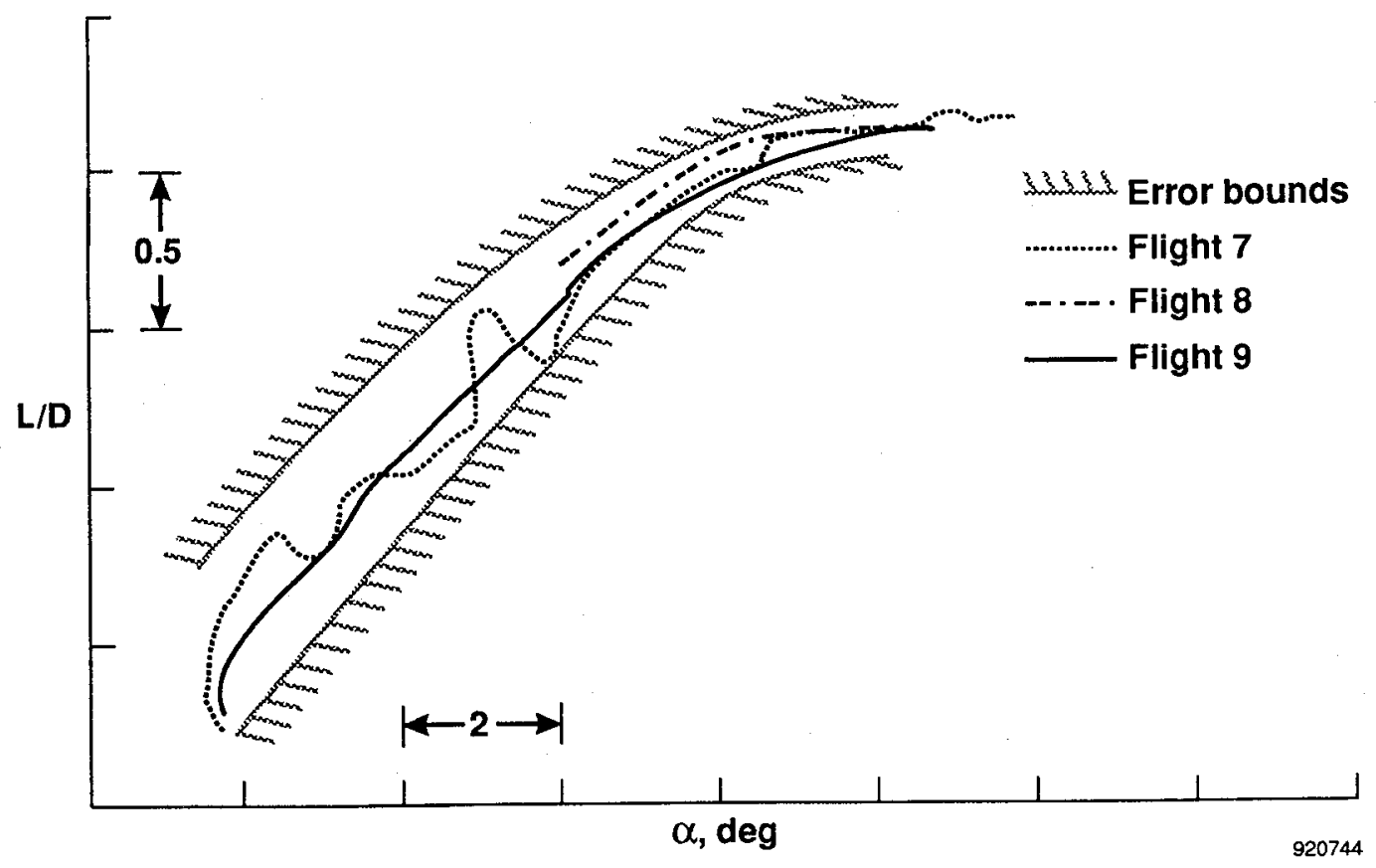

Fig. 8. Flight data repeatability.

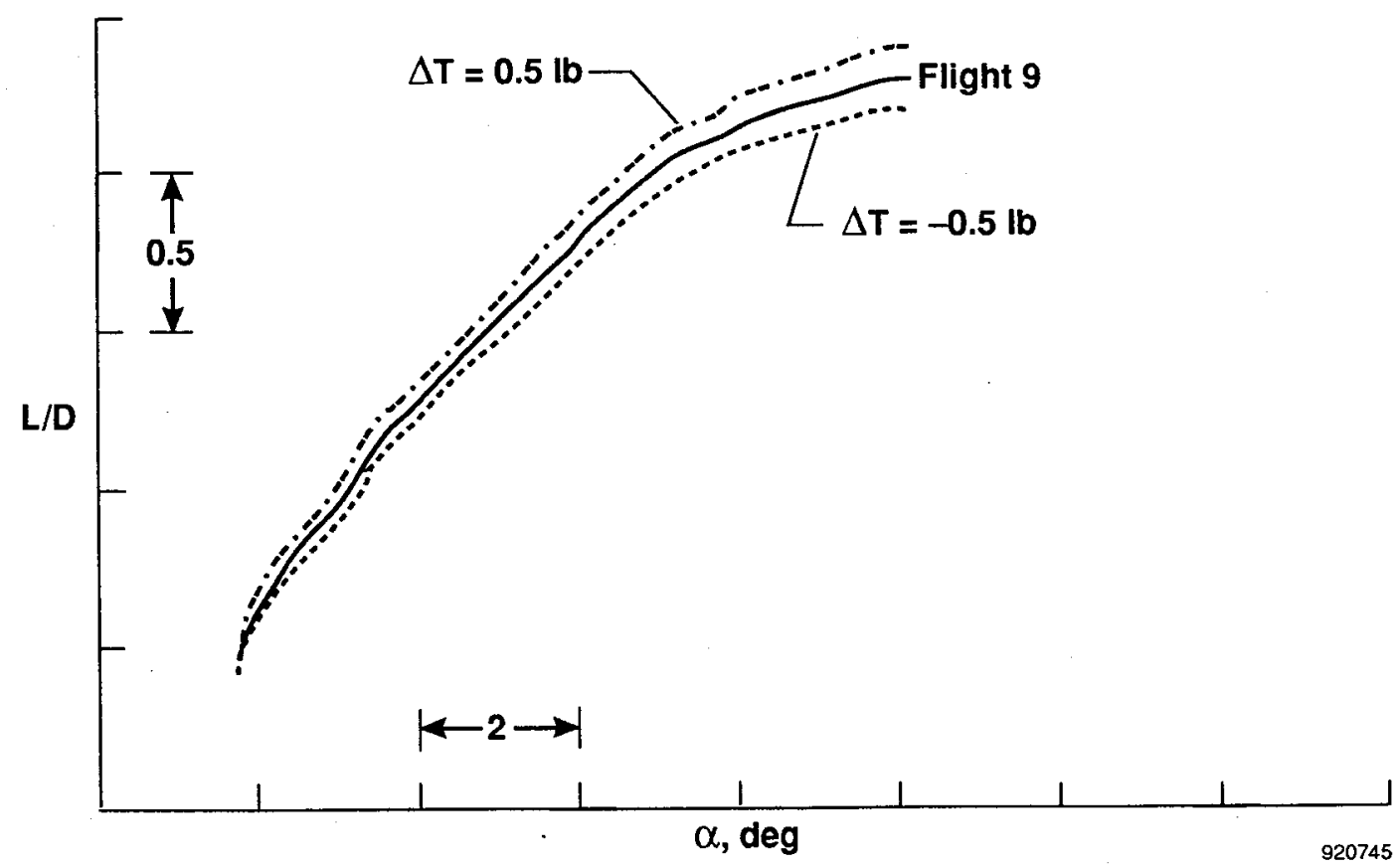

Fig. 9. Thrust measurement sensitivity. 


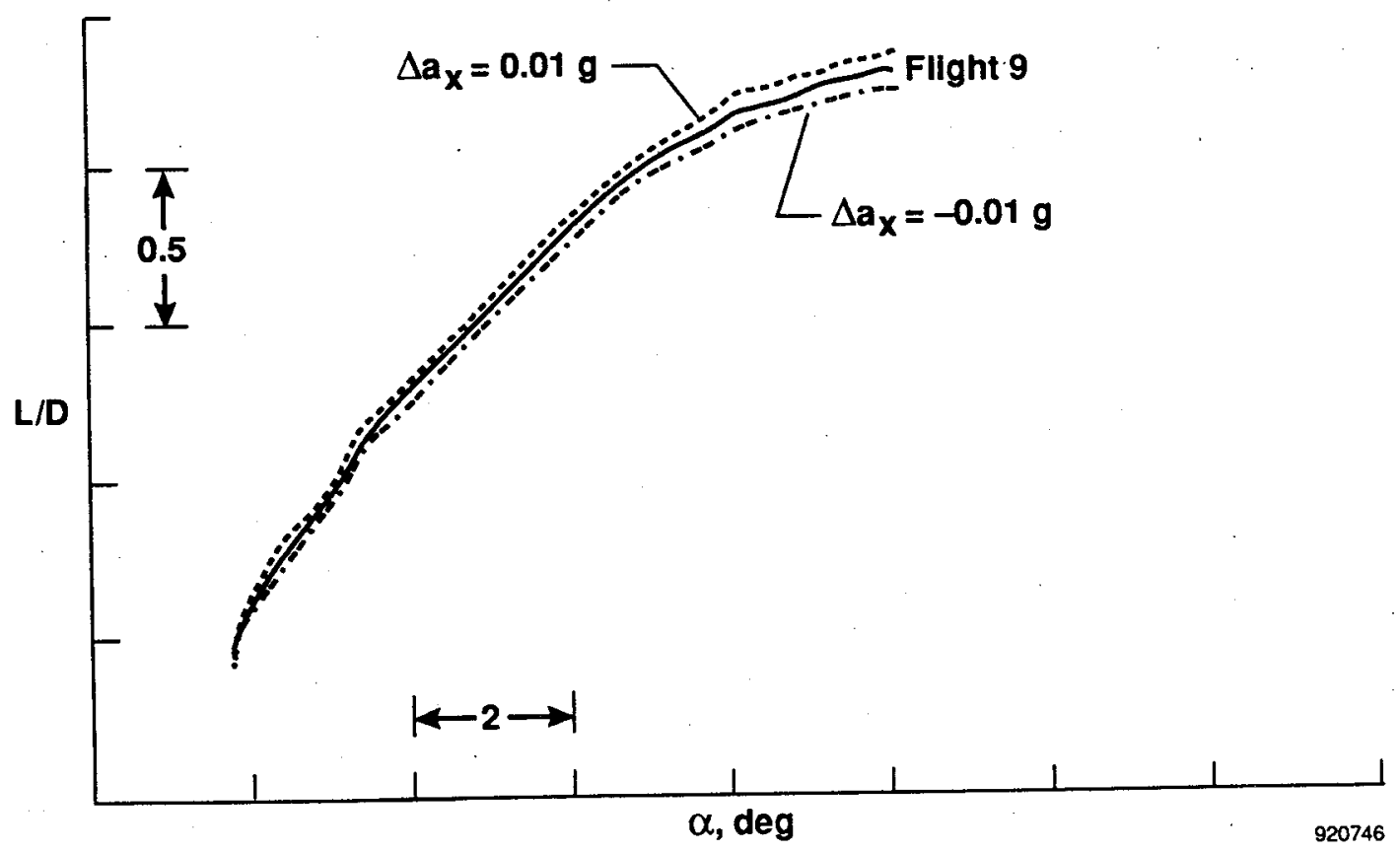

Fig. 10. Accelerometer measurement sensitivity. 


\section{REPORT DOCUMENTATION PAGE}

Publlc reponting burden for this collection of information is estimated to average 1 hour per response, including the time for revlewing instructlons, searching existing data sources,

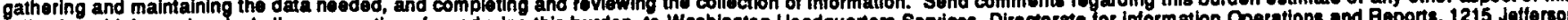
collection of information, including suggestlons for reducing this burden, of Wasnington Headguarters Serverwork Reduction Project (0704-0188), Washington, DC 20503.
1. AGENCY USE ONLY (LeAve blank)
2. REPORT DATE
January 1993
3. REPORT TYPE AND DATES COVERED
Technical Memorandum

4. TITLE AND SUBTITLE

Research Aspects of a Radio-Controlled Model Flight Test Program

6. AUTHOR(S)

WU 505-68-40

Gerald D. Budd (Dryden Flight Research Facility, Edwards, California);

Ronald L. Gilman and David Eichstedt (PRC Inc., Edwards, Califomia)

7. PERFORMING ORGANIZATION NAME(S) AND ADDRESS(ES)

8. PERFORMING ORGANIZATION

REPORT NUMBER

NASA Dryden Flight Research Facility

P.O. Box 273

H-1881

Edwards, Califomia 93523-0273

9. SPONSORING/MONITORING AGENCY NAME(S) AND ADDRESS(ES) AGENCY REPORT NUMBER

National Aeronautics and Space Administration

Washington, DC 20546-0001

NASA TM-104266

11. SUPPLEMENTARY NOTES

This report was prepared as AIAA paper 93-0625 for the 31st Aerospace Sciences Meeting, Reno, Nevada, January 11-14, 1993.

12a. DISTRIBUTION/AVAILABILITY STATEMENT

12b. DISTRIBUTION CODE

Unclassified - Unlimited

Subject Category 05

13. ABSTRACT (Maximum 200 words)

The operational and research aspects of a subscale, radio-controlled model flight test program are presented. By using low-cost free-flying models, an approach was developed for obtaining research-quality vehicle performance and aerodynamic information. The advantages and limitations learned by applying this approach to a specific flight test program are described. The research quality of the data acquired shows that model flight testing is practical for obtaining consistent and repeatable flight data.

14. SUBJECT TERMS

15. NUMBER OF PAGES 18

Radio control, Ducted fan engines, Free flight test apparatus

16. PRICE CODE

$\mathrm{A03}$

\begin{tabular}{l|l|l}
\hline 17. SECURITY CLASSIFICATION & 18. SECURITY CLASSIFICATION \\
OF REPORT & $\begin{array}{l}\text { 19. SECURITY CLASSIFICATION } \\
\text { On THIS PAGE } \\
\text { Onclassified }\end{array}$ & $\begin{array}{l}\text { OF ABSTRACT } \\
\text { Unclassified }\end{array}$ \\
\hline
\end{tabular}

20. LMITATION OF ABSTRACT OF REPORT 